\title{
La estigmatización de los
}

\section{estudios de personalidad en el \\ Sistema Penitenciario Mexicano}

The Stigmatization of Personality Studies in the

Mexican Penitentiary System

Anayely Mandujano Montoya ${ }^{1}$

Universidad Autónoma de Nuevo León

México

\section{Resumen}

El artículo presenta los aportes de estudios de personalidad clínicos criminológicos como un instrumento valioso para la ciencia criminológica, lo cual permite determinar las causas y los factores de la conducta antisocial. La metodología utilizada es de análisis documental, con la finalidad de comprender y disipar el estigma negativo de estos estudios, pues su incomprensión ha generado reformas legislativas que impactan directamente en el objetivo del Sistema Penitenciario Mexicano: la reinserción social. Se estudia la evolución de ese método criminológico, a fin de vislumbrar la necesidad del análisis y comprensión del sujeto. Además, brindan herramientas para la reincorporación de las personas privadas de libertad a la vida social de forma positiva y productiva, sin atentar contra los derechos humanos; más bien, el sentido del sistema penitenciario versa en dignificar el trato de las personas privadas de la libertad, salvaguardar sus derechos humanos, pero sin perder de vista que el objetivo final es la reinserción. Se hace énfasis en la necesidad de estos estudios de personalidad, realizados a personas privadas de libertad, ya que gracias a ellos se puede brindar un apoyo individualizado en el proceso de reinserción social, con el fin de evitar una recaída en las mismas causas que generan una conducta antisocial.

Palabras clave: Ejecución penal; sistema penitenciario; reinserción social; estudios de personalidad, criminología.

1 Doctora en Ciencias Políticas por la Universidad Autónoma de Nuevo León, Máster en Criminología. Correo electrónico: anayely.mandujano@gmail.com 


\begin{abstract}
The article presents the contributions of criminological clinical studies on personality as a valuable instrument for criminological science, which allows determining the causes and factors of antisocial behavior. The methodology used is a documentary analysis to understand and dispel these studies' negative stigma since their misunderstanding has generated legislative reforms that directly affect the Mexican Penitentiary System's objective: social reintegration. The evolution of this criminological method is studied to discern the need to analyze and understand the subject. Besides, they provide tools reintegrate people deprived of liberty into social life positively and productively, without violating human rights; instead, the meaning of the penitentiary system is to dignify the treatment of people deprived of liberty, safeguarding their human rights and keeping in mind that the ultimate goal is reintegration. The paper emphasizes the need for these personality studies on people deprived of liberty since, thanks to them, individualized support can be provided in the process of social reintegration to avoid recidivism in the same causes that generate antisocial behavior.
\end{abstract}

Keywords: execution of criminal sanctions; prison system; social reintegration; personality studies; criminology.

\title{
Antecedentes
}

La criminología es la ciencia que encuentra su sentido en el estudio de las causas de la conducta antisocial y de las personas que las cometen. Por ello, la definición que evocamos al referirnos a esta ciencia, es la de Alfonso Quiroz Cuarón como la ciencia sintética, causal explicativa, natural, cultural de las conductas antisociales (Rodríguez, 2013); no obstante, una de las dificultades que encuentra la ciencia criminológica es la limitada voluntad para explorar e indagar acerca de la etiología de la conducta criminal, pues tan solo existe un carácter represivo, sin que interese prevenir dichas conductas y, más bien, solo sancionar algunas de ellas de los individuos pertenecientes a los grupos soclales más desfavorecidos y con mayores carencias (Rios, 2017)

Referirnos a la conducta antisocial es referirnos a aquella que genera un daño social, o como lo señala Rodríguez (2012), es aquella que va contra el bien común, atenta contra la estructura básica de la sociedad, destruye sus valores fundamentales, lesiona las normas elementales de convivencia y viola los derechos humanos. Por ello, desde el escenario penitenciario, la criminología focaliza sus esfuerzos en identificar las causas y los factores individuales provenientes de la persona o del entorno social, en vías de contribuir a la reinserción social. 
De tal forma que la criminología que individualiza y enfoca su atención en las personas que han cometido conductas antisociales se conoce como clínica y de ella derivan los estudios criminológicos de personalidad, que establecen tanto los factores causales como características propias de la personalidad de las personas privadas de la libertad, lo que puede aportar información para conocer, por ejemplo, el régimen penitenciario recomendable, la capacidad de adaptación, sus factores de riesgo y aquellos de protección.

En este sentido, la Constitución Política de Estados Unidos Mexicanos establece, en su numeral 18, que el sistema penitenciario se organizará sobre la base del respeto a los derechos humanos, del trabajo, la capacitación para las personas, la educación, la salud y el deporte como medios para lograr la reinserción del sujeto sentenciado a la sociedad y procurar que no vuelva a delinquir.

Por su parte, la Ley General del Sistema Nacional de Seguridad Pública en México (2009) establece, entre otros fines de la Seguridad Pública, la reinserción social, además de desarrollar políticas en materia de prevención social del delito con carácter integral sobre las causas que generan la comisión de delitos y conductas antisociales; por lo anterior, el Estado deberá concentrar sus esfuerzos para lograr la reinserción social y, para ello, deberán llevarse a cabo políticas públicas eficaces, enfocadas en las causas que generan la conducta antisocial.

El Reglamento de los Centros Federales de Readaptación Social en México (1991), hasta antes de la Ley Nacional de Ejecución Penal (2016), consideraba los estudios de personalidad que practicaba la Dirección General de Prevención y Readaptación Social a través de un Consejo Técnico Interdisciplinario, además del perfil clínico criminológico de la persona interna, información relevante hasta ese momento para asignar un dormitorio, módulo, nivel, sección y para lo que en aquel momento se le denominaba "tratamiento"; no obstante, hoy día, se sustituye el término "readaptación social" por "reinserción social" y "tratamiento" por "actividades de reinserción social" partiendo del hecho de comprender que una persona que ha cometido una conducta antisocial no es desadaptada ni enferma para recibir un tratamiento, sino se concibe a la persona privada de la libertad como sujeto de derechos, uno de los cuales es el recibir apoyo a través del personal penitenciario para favorecer su proceso de reinserción social, concepción difícil de comprender para la corriente crítica, que considera se impone un estigma social, que marca la pauta para la discriminación y el rechazo.

Esta corriente crítica encuentra las causas de la criminalidad en el proceso de criminalización, esto es, en el poder de definición, asignación y ejecución que es 
atribución del poder punitivo, el cual es ejercido de manera desigual, selectiva y discriminatoria en perjuicio de las personas pertenecientes a los grupos sociales más carenciados y vulnerables de la sociedad (Ríos, 2017); sin embargo, al ser la conducta antisocial el objeto de estudio de la criminología, resulta imposible prescindir del estudio de las causas, como también el excluir las normas jurídicas y el contexto cultural.

Jean Pinatel (1981), por ello, considera esta postura crítica, como la anticriminología, pues no solamente se pone de parte del sujeto "delincuente", sino también se pone de parte de la clase a la que pertenece, en la que acentúa las relaciones de dependencia, explotación, manipulación del ente débil por el fuerte, por lo que distingue tres niveles de interpretación: El conductual, es decir, la conducta antisocial; el personal, la persona que comete una conducta antisocial y el general, es decir, el conjunto de conductas antisociales en determinado lugar y tiempo.

Por lo anterior, los estudios de personalidad son instrumentos que parten del nivel de interpretación personal y necesaria para la comprensión del nivel conductual y general de la conducta antisocial. En el caso de México, la Primera Sala de la Suprema Corte de Justicia de la Nación (SCJN) resolvió, en sesión de 30 de marzo de 2016, el amparo en revisión 1003/2015, en el cual determinó la inconstitucionalidad de la fracción II del artículo 84 del Código Penal Federal, es decir, de los "estudios de personalidad", y refiere que tratándose de la libertad preparatoria, viola el principio de reinserción social previsto en el artículo 18 constitucional.

Derivado de esta interpretación, la Suprema Corte de la Nación consideró inconstitucional la obligatoriedad de estudios de personalidad que eran determinantes para un beneficio de preliberación, con el argumento de que no era adecuado considerar la ausencia o presencia de determinadas cualidades morales o de personalidad, sino que era necesario basarse "en actos objetivos y concretos" que permitieran sostener que el sujeto sentenciado se reinsertaría satisfactoriamente a la sociedad. Esta determinación parte de la interpretación de que el examen de personalidad "se convertiría en un instrumento de control de personalidades desviadas a juicio de un grupo de especialistas y la negativa del beneficio preliberacional se traduciría en el 'fracaso del tratamiento' instaurado en el presidio, lo cual no hace sentido con el nuevo paradigma contenido en el artículo 18 de la Constitución".

Esta resolución (Zaldivar, 2015) resaltó que la reinserción social no puede depender de un cambio psicológico o de forma de pensar y de sentir de la persona interna; sin embargo, es importante señalar que, si bien no puede depender, sí 
debe ser considerado, dado que influye en la toma de decisiones para reincidir en la conducta delictiva o reinsertarse socialmente.

Así mismo, se señaló que en México la sobrepoblación en los centros penitenciarios impide actividades recreativas, culturales y deportivas para las personas internas, condición que retarda la libertad anticipada a la que tienen derecho quienes ya recibieron sentencia, pues precisamente uno de los requisitos para obtenerla es haber cumplido con ellas mientras se estuvo en reclusión, por lo que es obligación otorgar los beneficios de libertad mediante criterios objetivos y verificables como lo recomienda la Comisión Interamericana de Derechos Humanos (CIDH, 2008), en función de su comportamiento y capacidad laboral y no por algún estudio de personalidad.

En este nivel de entendimiento, se evidencia que la preocupación real era el no poder contar con herramientas "objetivas" que volvieran más accesible el beneficio de preliberación, por no estar al alcance de todos los grupos, pero no olvidemos que en primera instancia se trata de un beneficio, es decir, las personas fueron privadas de la libertad y en su caso se les otorgó una sanción por parte de una autoridad judicial, así que acceder a este beneficio era considerado la excepción y no la regla; por otra parte, la verdadera solución no recae en depurar los centros de reinserción social por volverse insostenibles ante la ausencia de gobernabilidad, ni volvernos liberalmente ingenuos o ingenuas, como señala Petersilia (2003): el reto real es hacer que el "sistema" funcione.

Respecto de la gobernabilidad, nos referimos a ella para hacer alusión a la relación entre las autoridades y las personas privadas de la libertad, la cual permite a la autoridad cumplir efectiva y legítimamente los objetivos de las instituciones y los procesos que ahí se desarrollen, además de mantener el control efectivo de la autoridad en los centros de reinserción social, por lo que la gobernabilidad resulta imprescindible para preservar la dignidad humana.

Por su parte, la Ley Nacional de Ejecución Penal en México surge en el año 2016, con el estandarte de no violentar los derechos humanos de las personas privadas de libertad; esta mejora la calidad de vida en prisión. Sarre (2015) -impulsor de esta iniciativa- enfatizó el interés en que se deje de percibir a la persona privada de la libertad como una persona enferma, que no se le considere como objeto de tratamiento y sí como sujeto de derecho.

Lo anterior llevó a que, desde esta interpretación de la criminología, se considerará subjetivo todo aquel criterio que utilizaba el equipo técnico interdisciplinario de los centros de reinserción social en México al hacer "el estudio de 
personalidad"; sin embargo, la concepción de tratar a la persona privada de la libertad como una persona "enferma" se eliminó desde aquel momento en el que se dejó de hablar de "readaptación" para sustituir el concepto por "reinserción" en la reforma constitucional del año 2011. Quizá por interpretación literaria de la palabra "tratamiento" exista una resistencia, al hablar de factores de riesgo o características propias de la personalidad, que nos hacen comportarnos de una u otra forma, aplicable para cualquier persona, además de la capacidad que existe de transformar nuestra propia persona, sobre todo cuando intervienen especialistas.

La Ley Nacional de Ejecución Penal, en efecto, aparece en México con una visión noble, ha establecido un parteaguas para el sistema penitenciario y, con ello, apremia a todas las instituciones privativas de la libertad a adecuarse con un sentido humano e innovador en la concepción del internamiento; sin embargo, si bien es cierto que no establece el estudio de los componentes de personalidad de los sujetos como un elemento necesario para obtener un beneficio de preliberación, lo cierto es que el mandato constitucional es procurar que no vuelva a delinquir, de tal forma que, intrínseca e indirectamente el estudio de estos factores, para establecer el plan de actividades individualizado, es inherente.

Para ser claros, esta Ley se presentó como respuesta ante la evidente ingobernabilidad de los centros de reinserción social y la crisis en el Sistema Penitenciario Mexicano en los últimos años, sin que ella sea la respuesta a la problemática que, en efecto, se presenta. No obstante, lo bueno es que se buscó una solución; lo malo, el problema en realidad no era el problema, sino la consecuencia de la ingobernabilidad en las prisiones, lo cual nos llevó a volvernos liberales y, además, tratarlo con ingenuidad, como para abrir la puerta a un problema que el Estado ya no pudo sostener, según Petersilia.

\section{El trabajo criminológico en la Ley Nacional de Ejecución Penal}

Para comenzar, es importante partir de la definición de reinserción social establecida en la Ley Nacional de Ejecución Penal en su numeral cuatro, que la refiere como la restitución del pleno ejercicio de las libertades tras el cumplimiento de una sanción o medida ejecutada con respeto a los derechos humanos; esta definición es limitada respecto al verdadero sentido de la reinserción social, pues alude únicamente a devolver las libertades a la persona privada de la libertad tras cumplir una sanción, agrega -muy acertadamente- siempre con respeto a sus derechos humanos; sin embargo, desde aquí se origina la primera parte del problema, pues resulta ante una interpretación completamente jurídica literaria de "reinserción social", es decir, el abrir la puerta y colocar al sujeto en la sociedad. 
La definición anterior nos remonta a un momento histórico en el que el objetivo de la pena privativa de la libertad era únicamente el castigo, la institución solo contiene y el tiempo en internamiento realiza actividades en espera del tiempo perdido que le roba la prisión como consecuencia del delito que le llevo ahí mismo. Esta visión lejos está de avanzar hacia la visión legítima de reinserción social y, por el contrario, cada vez más se acerca al encierro.

Por otra parte, los centros de reinserción social son las instituciones encargadas de salvaguardar a aquellas personas privadas de la libertad que, por resolución de un juez, se encuentran en internamiento. En las instituciones existe un equipo técnico multidisciplinario denominado "Comité" o "Consejo" conformado por profesionales de la criminología, psicología, trabajo social, pedagogía y demás especialistas que abordan el estudio de forma multidisciplinaria. Ríos (2017) señala que la multi, trans e inter disciplinariedad siempre da buenos resultados, porque la realidad no se presenta dividida, por lo que, entre sus funciones está el determinar la ubicación que le corresponde a cada persona privada de la libertad al ingresar al centro, de tal forma que deba separarse a las mujeres de los hombres, luego de su procesamiento y sentencia inimputable, en prisión preventiva y ejecución; las personas que estén por delincuencia organizada o sujetas a medidas especiales se destinarán a espacios especiales, de acuerdo con la Ley Nacional de Ejecución Penal de México.

En este orden de ideas, al leerse literalmente, la Ley Nacional de Ejecución Penal y con los argumentos de sus agentes impulsores, ella no contempla los estudios de personalidad ni el trabajo técnico con el valor que anteriormente se les atribuía por considerarse una labor "subjetiva" y que "violenta" los derechos humanos de las personas privadas de la libertad con los llamados "estudios de personalidad"; recae, así, el valor en la conducta disciplinaria y en el cumplimiento de las actividades, las cuales, a propósito, ni una ni otra se traducen íntegramente en avances de reinserción social. De tal forma, la percepción que prevalece es la jurídica y no la focalizada en conocer las causas de la conducta antisocial, su capacidad de adaptación o el riesgo institucional, entre otros. Bien lo menciona Palacios (2017), el juez o la jueza no entenderá los estudios clínico-criminológicos que penitenciaristas le pongan a la vista y, seguramente, tendrá dudas genuinas sobre los fundamentos de cada dictamen.

No obstante, el reto ante esta percepción es clarificar que el trabajo criminológico radica en identificar las causas de la conducta antisocial, es decir, los factores de riesgo que llevaron al sujeto al "paso al acto" como suelen referirse desde la criminología clínica al momento justo en el que comete la conducta antisocial. 
Pues acumular datos no genera ciencia, es preciso seleccionarlos e interpretarlos, a través de una síntesis (Orellana, 2016).

Identificar los factores de riesgo en las personas privadas de la libertad, a través de los "estudios de personalidad" como se les denominaba anteriormente, tiene la finalidad de brindar, por medio de la institución, las herramientas para que puedan reincorporarse a su vida social de forma positiva y productiva, de ninguna forma buscando estigmatizar al sujeto o atentar contra sus derechos humanos; más bien, el sentido del sistema penitenciario versa en dignificar el trato de las personas privadas de la libertad, salvaguardar sus derechos humanos, pero sin perder de vista que el objetivo final es la reinserción.

Entonces, el objetivo es ayudar al sujeto a identificar las carencias y áreas de oportunidad que le permitan salir adelante; omitir esta parte lleva a considerar el internamiento únicamente como una contención del problema, ver la pena solo como un castigo y no como la forma de reinsertarle. En efecto, hay que estudiar científicamente el problema antisocial antes de intervenir en la reacción social contra la persona antisocial, pues la conducta antisocial no solo es un problema individual, sino un grave problema comunitario (Molina, 2016).

Según Pinatel (1981), el paso al acto es aquel en el que una persona cruza la línea y comete una conducta antisocial; mientras que otros individuos, en las mismas circunstancias, se detienen y controlan sus impulsos. Por tanto, si no se atienden los factores que coadyuvaron al paso al acto de la conducta antisocial o, si en primera instancia, se desconocen, no hay manera de brindar el apoyo individualizado que la persona necesita para reincorporarse positivamente a la sociedad.

La Ley Nacional de Ejecución Penal en su numeral 31 refiere que la autoridad penitenciaria estará obligada a instrumentar una clasificación de las distintas áreas y espacios en el centro penitenciario, en particular, de los dormitorios, obedeciendo a criterios basados en la edad, el estado de salud, duración de la sentencia, situación jurídica y otros "datos objetivos" sobre las personas privadas de la libertad, tendientes a armonizar la gobernabilidad y la convivencia entre las personas privadas de la libertad.

Por lo que, al referir datos objetivos, se evidencia la duda e incredulidad respecto a la ciencia criminológica al momento de realizar los dictámenes criminológicos que identifiquen la génesis de la conducta; pero, a su vez, el mandato reitera el objetivo de la búsqueda de gobernabilidad al interior de los centros de reinserción social, dejando corta la función de clasificación, de tal forma que el hacerlo por edad, situación jurídica o sexo, sin considerar las características de personalidad, 
poco se alinea con este ordenamiento; resalta, además, que la prisión por sí misma no tiene la capacidad de resocializar a las personas privadas de la libertad.

\section{La contraposición inexistente del trabajo criminológico y los derechos humanos}

No existe una contraposición del trabajo criminológico penitenciario versus los derechos humanos; de hecho, se parte del supuesto de que es un derecho de las personas privadas de la libertad que la autoridad les brinde herramientas reinsertivas acordes a su individualidad para reintegrarse favorablemente al entorno en el que se desenvuelven.

La importancia del trabajo criminológico en los centros de reinserción social y la interpretación literaria de la Ley Nacional de Ejecución Penal han derivado en confusión respecto al rol del personal penitenciario; no obstante, en su numeral 5 establece que la autoridad administrativa podrá establecer sistemas de clasificación de acuerdo con los criterios de igualdad, integridad y seguridad. Esto abre la puerta para considerar que el criterio de seguridad incluye las características de personalidad, pues la agresividad, indiferencia afectiva, egocentrismo, bajo control de impulsos, labilidad, entre otros, son elementos de la propia personalidad que pueden percibirse o identificarse según el trabajo criminológico, por lo que, es necesario comprender que la clasificación únicamente por sexo, edad o situación jurídica no es suficiente para mantener un régimen penitenciario apropiado ni para evitar el riesgo institucional y la contaminación criminal.

Sin embargo, en lo que respecta a los criterios de beneficios de preliberación, estos se han centrado en la disciplina y el cumplimiento de actividades, lo cual resulta riesgoso, pues de no hacerlo con los criterios correctos, daremos fin a un problema penitenciario: la sobrepoblación; pero, al abrir las puertas a personas que aún no tienen las herramientas reinsertivas, generaremos un problema social con probabilidad de reincidencia latente.

\section{La "subjetividad" del trabajo criminológico}

Cuando hablamos del trabajo criminológico, nos enfrentamos a muchos paradigmas. Bien lo señala Palacios (2017), los prejuicios en torno a la peligrosidad criminal, que le dieron gran auge y prestigio a la criminología, hoy le hacen mucho daño: caricaturizan el trabajo serio de la criminología clínica, ponen en duda la calidad de verdad de sus conclusiones, descalifican sus métodos, desautorizan sus instrumentos y devalúan su profesión. 
Considerar subjetivo el estudio de la personalidad seria tal como restarle a la psicología y la criminología el valor de ciencia, pues la falta de entendimiento por parte del derecho les da una denominación de subjetividad, cuando en realidad son ciencias en las que su estudio les permite contribuir al trabajo penitenciario.

Por lo anterior, es preciso señalar que hay criminología clínica practicada en países como Estados Unidos, Canadá, Reino Unido y Australia, e incluso en algunos de América como lo es Argentina; sin embargo, en México no existen políticas públicas que se basen en estudios clínicos para determinar las causas de la criminalidad, prevenirla, disminuirla o controlarla y, por lo tanto, es omitida en sus legislaciones, como lo fue en la Ley Nacional de Ejecución Penal.

Con gracia evocamos aquel momento en el que Palacios (2017) mencionó, respecto del escepticismo clínico, lo siguiente: "Lo que yo sé es que tú eres menos peligroso que Charles Manson. Si estás de acuerdo, entonces deberás admitir que la peligrosidad tiene dimensiones. Si tiene dimensiones, luego puedo medirse. Si puede medirse, esa medición debe ser científica" y, entonces, retomamos aquella frase de Aristóteles que señalaba: los mayores delitos están causados por el exceso y no por la necesidad (Jowett, 1908); contrario a lo que asume la corriente crítica, pues hay quienes asumen que la pobreza, la desigualdad y la exclusión social, resultantes del proceso de dominación, son las verdaderas causas del crimen (Peñaloza, 2010), lo cual tiene sentido; sin embargo, agregaría que estos factores influyen pero no determinan la conducta antisocial, después de todo el entorno es el mismo para gran cantidad de gente y no por ello influye igual para todas las personas, de tal forma, que el análisis de las causas individuales a través de los estudios de personalidad son de gran relevancia.

Partir de que los estudios de personalidad no son necesarios por ser "subjetivos" sería tal como admitir que el tratamiento psicológico establecido para las víctimas a través de una autoridad en realidad no se considera funcional o que la interdisciplinariedad de la criminología no comprendida ante juristas la hace vulnerable como ciencia; no obstante, tales estudios dan respaldo y consultoría técnica a las decisiones de las autoridades judiciales, tanto para la identificación del plan individual de ejecución como para la medida sancionadora y para las autoridades penitenciarias, para establecer el régimen penitenciario y el seguimiento de los objetivos en internamiento.

Así mismo, con mayor peso, actualmente la ley se centra en un plan de actividades y programas institucionales para lograr la reinserción social y que el sujeto no vuelva a delinquir, por lo que estas actividades deben ser individualizadas de acuerdo con las necesidades y los factores de riesgo de cada persona privada de la 
libertad, de tal forma que esto no es posible sin la intervención de la criminología, pues la ley contempla diseñar, con participación de la persona interna, los planes de actividades y no hay manera de hacer un plan de actividades que funcione para reinsertar a la persona privada de la libertad sino es con su participación en el trabajo criminológico y multidisciplinario, para poder identificar los factores de riesgo por contrarrestar, para procurar que no vuelva a delinquir, y ello se logra a través de los estudios clínico criminológicos.

En este orden de ideas, para la criminología clínica, la adaptabilidad no es opuesta a una personalidad antisocial; de hecho, en algunos casos se habla de una mayor peligrosidad cuando hay una adaptabilidad social combinada con una capacidad criminal elevada, sin que eso sea obstáculo para comportarse de acuerdo con lo esperado, el nivel de riesgo de una persona privada de la libertad no lo determina su comportamiento, pues hay personalidades con la capacidad de ser líderes negativos que, sin involucrarse, pueden influir en sus pares y causar más daño del previsto con su comportamiento disciplinario. Con esta perspectiva, con este perfil de la personalidad, se favorece a los sujetos privados de la liberad.

El riesgo: este mismo criterio se aplica para el otorgamiento de libertades anticipadas o modificación de medida.

$\mathrm{Al}$ respecto, en el caso de beneficios preliberacionales se establecen dos requisitos: el primero consiste en el buen comportamiento, ausente de sanciones disciplinarias; el segundo, que realice actividades educativas, culturales, laborales, etc. Rueda (2018) sostiene que lo anterior es una forma de política criminal que busca incentivar o motivar la participación de las personas sentenciadas en las bases elementales del sistema penitenciario mexicano, pues solo a través de ellos es susceptible de lograrse la reinserción y procurar que no vuelva a delinquir; sin embargo, aunque las actividades productivas coadyuvan a su buen desempeño, si no se atienden las cuestiones de la personalidad que lo llevaron al paso al acto, de nada servirá que consiga un empleo, si los factores de riesgo que lo llevaron al robo, nunca fueron atendidos, por citar un ejemplo.

La Ley Nacional de Ejecución Penal, en esencia garantista, salvaguarda una perspectiva de género y derechos humanos, avances significativos en México; sin embargo, excluye los estudios de personalidad por considerarlos subjetivos, sin atender que distorsiona los criterios de reinserción social limitándolos al buen comportamiento y cumplimiento de actividades que generan una adaptabilidad simulada con la única intención de obtener un beneficio, lo que evidentemente no tiene nada que ver con la reinserción social. 
Contrario a lo que se ha señalado, en la práctica de algunos centros de reinserción social de México se ha omitido el trabajo criminológico con el argumento de que este, por ser subjetivo, ya no deberá ser considerado o realizado. Ruíz (2018) señala que el plan de actividades establecido en la Ley Nacional de Ejecución Penal debe incluir las siguientes etapas:

i. Estudio y Diagnóstico. Durante este período el personal técnico del Centro Penitenciario realizará el estudio de personalidad de la persona privada de la libertad para determinar la ubicación y el tratamiento que le corresponda y la forma en que se desarrollará.

ii. Ubicación. De acuerdo con las características de las personas como género, perfil criminológico, estado de discapacidad mental y físico, entre otras y las circunstancias de seguridad que determine la autoridad administrativa penitenciaria, se confinará a las personas privadas de la libertad a un lugar en específico.

iii. Tratamiento. Se diseñará con base en los resultados de los estudios técnicos que se le hayan practicado, los cuales deberán ser actualizados semestralmente para ser analizados en el Comité Técnico.

iv. Reincorporación Social. Se inicia con la obtención de la libertad, en cualquiera de sus modalidades.

Así que, el trabajo criminológico penitenciario en los centros de reinserción social es fundamental para continuar avanzando en la búsqueda del alcance de los objetivos establecidos. Países desarrollados tienen criminología avanzada aplicada, de tal forma que el hecho de que en México no sea conocida llevó a su omisión, de tal forma que los esfuerzos en México deberían ser enfocados en especializarnos en criminología clínica y no en desaparecerla.

\section{Conclusión}

Los estudios de personalidad clínico criminológicos resultan un instrumento valioso de la ciencia criminológica, la cual encuentra su fundamento en las causas de la conducta antisocial y en las personas que la cometen; ello, visto desde diferentes concepciones: desde la general, es decir, de la criminalidad en cierto tiempo y lugar; conductual, esto es, desde el estudio de la conducta en sí misma, o del personal, desde el sujeto antisocial.

Por lo anterior, para su estudio no podemos prescindir del nivel de análisis de la conducta antisocial y de la persona que la realiza, lo cual la lleva al internamiento 
en un centro de reinserción social, y mucho menos prescindir de las causas y factores que influyeron para el "paso al acto".

En este sentido, estos instrumentos han dejado atrás aquel abordamiento primitivo que estigmatiza a la criminología clínica, para sustituirlo por una identificación de factores de riesgo que llevaron a la conducta antisocial y el fortalecimiento de factores de protección con los que cuente la persona, por lo que es necesario, sí, un replanteamiento que consolide estos instrumentos, pero no su anulación.

De tal forma, que es fundamental, para el cumplimiento de los objetivos del Sistema Penitenciario, como lo es la reinserción social, pues no hay manera de brindar herramientas que coadyuven a la reincorporación positiva y productiva de una persona privada de la libertad, sin la comprensión y análisis de aquellos elementos que se conjugaron dando como resultado la conducta antisocial y que, además, de no hacerlo con esta visión, eliminaría el sentido de este objetivo de reinserción social sustituyéndolo por simple contención.

Esta incomprensión llevó, en México, a la anulación de estos estudios restándoles valor. Sin duda, hubo un avance significativo con la aparición de la Ley Nacional de Ejecución Penal, pero ella no puede opacarse por dejar de lado la intervención multidisciplinaria de las ciencias como un medio para reinsertar a las personas privadas de la libertad. Considerar estos instrumentos individualizados que toman en cuenta las características de la propia personalidad implica incorporar esas herramientas reinsertivas; pero, en contraparte, tener en cuenta solo en el cumplimiento de una actividad y su historial disciplinario resulta riesgoso y limitante, puesto que el acato de normas en un medio simulado no necesariamente significa una modificación de esos factores que llevaron al paso al acto y mucho menos se traduce en reinserción social o en la no reincidencia.

Con ello, es preciso señalar que la visión de la Ley Nacional de Ejecución es importante, es trascendental; de hecho, el problema no es la ley, sino la interpretación de la ley; lo peligroso es la trascendencia cuando van acompañadas de una interpretación literaria de esta misma. Omitir el estudio de los factores de riesgo derivados de un estudio criminológico no permitirá establecer un plan de actividades individualizado destinado a contrarrestarlos y, por lo tanto, no se brindarán herramientas reinsertivas en beneficio de la persona privada de la libertad, lo cual también es parte de sus derechos y obligación del Estado.

Así mismo, es importante comprender que la reinserción social no se traduce únicamente en liberar a una persona privada de la libertad después de una sanción, 
que los centros de reinserción social no son sitios de contención o encierro y que el trabajo criminológico no es opuesto a los derechos humanos.

En este sentido, se debe cuidar también que el resultado de anular los estudios clínicos criminológicos no sea una respuesta que busque, de forma implícita, una liberación accesible, como respuesta a la crisis del Sistema Penitenciario, que más bien, deriva de una problemática distinta, como lo es la ausencia de gobernabilidad al interior de las instituciones. Por lo tanto, el argumento sostenido para eliminar los estudios de personalidad en la legislación con la intención de que las prisiones sean un espacio con ley y que el Estado de Derecho impere en la prisión (Sarre, 2015), en efecto, es prioritario; pero la respuesta que se da a este planteamiento es solo una pieza del eslabón, pues lo realmente importante es lograr tener el control efectivo sobre las instituciones penitenciarias para garantizar la gobernabilidad en los centros de reinserción social: abrir las celdas no solucionará el problema.

No obstante, es preciso agregar que para la gobernabilidad es necesario contar con elementos de seguridad, control, ausencia de violencia, entre otros, por lo que una clasificación acorde permitirá establecer el régimen penitenciario adecuado para evitar el riesgo institucional. Aplicar únicamente criterios como el historial disciplinario y el cumplimiento de actividades no corresponde con los criterios de reinserción social ni garantiza la no reincidencia.

El reto principal en el Sistema Penitenciario no versa en la legislación, sino en la capacidad de los Estados para implementarlas de forma efectiva, en ampliar su visión y el criterio para comprender que el trabajo de la ciencia criminológica contribuye en las personas privadas de la libertad y permite garantizar que se les brinden herramientas para reintegrarse a su entorno social de manera positiva, como parte importante de la protección de sus derechos humanos, al reconocer que las personas privadas de la libertad tienen la capacidad de transformarse a sí mismas, y que los esfuerzos deben concentrarse en resolver el problema de fondo y no únicamente de forma.

\section{Referencias}

Comisión Interamericana de Derechos Humanos. (2008). Principios y buenas prácticas sobre la protección de las personas privadas de la libertad en las Américas. http:// www.oas.org/es/cidh/mandato/Basicos/PrincipiosPPL.asp

Diario Oficial de la Federación. (2 enero, 2009). Ley General del Sistema Nacional de Seguridad Pública. Autor. http://www.diputados.gob.mx/LeyesBiblio/pdf/LGSNSP.pdf 
Diario Oficial de la Federación. (Junio, 2016). Ley Nacional de Ejecución Penal.Autor. www.diputados.gob.mx/LeyesBiblio/pdf/LNEP.pdf

Jowett, B., \& Davis, H. (1908). Aristotle's politics. Clarendon Press

Molina, A. (2016). Criminología. Una introducción a sus fundamentos teóricos para juristas. Tirant lo Blanch.

Orellana, O. (2016). Manual de Criminología, Prorrúa. http://metabase.uaem.mx/bitstream/handle/123456789/2727/479_1.pdf?sequence $=1$

Palacios, G. (2017). Criminología clínica contemporánea. Porrúa

Peñaloza, P. (2010). La antigüedad del presente. Defensa del futuro. En P. Peñaloza (Coord.), Narcotráfico, crisis social, derechos humanos y gobernabilidad. Una agenda para el futuro. Porrúa.

Petersilia, J. (2003). When Prisoners come Home: Parole and Prisoners Reentry. University Press.

Pinatel, J. (1981). Nuevas sendas de la criminología, exploraciones interdisciplinarias e interculturales; recopilación de trabajos en honor del criminólogo Karl Otto Christiansen; Criminología: Punto crítico en su historia. Edit. Abeledo-Perrot.

Ramírez, J. (4 abril, 2016) Inconstitucional exámenes de personalidad para preliberación. Sipse. https://sipse.com/opinion/inconstitucional-examenes-de-personalidad-para-preliberacion-198914.html

Redacción (30 de marzo, 2016). SCJN: Declara inconstitucional aplicación de exámenes de personalidad para conceder beneficios de preliberación. Revista Jurista http:// revistajurista.com/scjn-declara-inconstitucional-aplicacion-de-examenes-de-personalidad-para-conceder-beneficios-de-preliberacion/

Reglamento de los Centros Federales de Readaptación Social. Publicado en el Diario Oficial de la Federación. (1991). México. http://ordenjuridico.gob.mx/Publicaciones/ pdf/R120.pdf

Ríos, J. (2017). La herencia de la criminología clínica. Horizonte México, 17(2), 71-76 Recuperado de https://dx.doi.org/https://doi.org/10.24265/horizmed.2017.v17n2.10

Rodríguez, L. (2012). Criminología clínica. Porrua

Rodríguez, L. (2013). Introducción a la criminología. Porrua.

Rueda, M. (2018) Beneficios preliberacionales. Libertad condicionada y libertad anticipada. Digital de la Reforma Penal. Ley Nacional de Ejecución Penal, 6, 22. http://www.poderjudicialcdmx.gob.mx/wpcontent/uploads/Revista_Nova_Iustitia_Febrero_2018.pdf 
Ruíz, A. (2018) El plan de actividades. Revista Digital de la Reforma Penal. Ley Nacional de Ejecución Penal, 6, 22. http://www.poderjudicialcdmx.gob.mx/wp-content/ uploads/Revista_Nova_Iustitia_Febrero_2018.pdf

Sarre, M. (2015). Ley Nacional de Ejecución Penal. https://www.youtube.com/ watch? $\mathrm{v}=\mathrm{hxhj} 41 \mathrm{HKIz} 4$

Zaldivar, A. (2015). Amparo 1003/2015. www.supremacorte.gob.mx 